\title{
VIABILIDADE DOS GRÃOS DE PÓLEN DE FLORES DE PINHEIRA (Annona squamosa) EM DIFERENTES HORÁRIOS
}

\author{
Viability of the sugar apple (Annona squamosa) pollen grains at different hours of the day
}

\author{
Silvia Nietsche ${ }^{1}$, Marlon Cristian Toledo Pereira ${ }^{2}$, Carpegiane Oliveira ${ }^{3}$, Márcia Maria Dias ${ }^{4}$, Sidnei Tavares dos Reis ${ }^{5}$
}

RESUMO

No manejo do cultivo da pinha (Annona squamosa), a polinização artificial é uma prática preconizada para, obter maior pegamento dos frutos bem como uniformização do formato dos mesmos. Nesse sentido, conduziu-se este trabalho, com o objetivo de avaliar a viabilidade dos grãos de pólen de flores de pinheira em diferentes horários de coleta. O pólen foi obtido a partir de flores no estádio funcionalmente estaminada. Foram avaliados oito horários de coleta de pólen: zero hora, 1 hora, 2 horas, 3 horas, 4 horas, 5 horas, 6 horas e 7 horas da manhã. Foi utilizado meio de cultura padrão para germinação de pólen, com concentração de $10 \%$ de sacarose. As flores foram coletadas nos horários estabelecidos e os grãos de pólen foram retirados das anteras com auxílio de um pincel número 2 e em seguida inoculados em placas de Petri contendo o meio de cultura. O delineamento experimental foi inteiramente casualizado com quatro repetições, sendo cada parcela experimental constituída por duas placas Petri. Foram contados 100 grãos de pólen por placa. Após 6 horas de inoculação, os grãos de pólen foram visualizados sob lupa. Foram considerados germinados os grãos de pólen que possuíam tubo polínico com tamanho igual ou superior ao diâmetro do próprio pólen. Não foram observadas diferenças significativas entre o horário de coleta dos grãos de pólen. A percentagem média da germinação variou de 46,75\% a 53,62\% dos grãos de pólen germinados.

Termos para indexação: Annona squamosa, manejo da polinização, germinação de pólen in vitro.

\section{ABSTRACT}

In the management of the sugar apple (Annona squamosa) crop, the artificial pollination is a preconized practice to obtain higher establishment of the fruits as well as their standardization. This study was carried out to evaluate the viability of sugar apple pollen grains at different collecting times. The pollens were obtained from the flowers at the functional staminate stage. The pollen grains were collected every hour, starting from 00:00am and ending at 07:00am, totalizing 8 collections. The standard culture medium with $10 \%$ sucrose was used for the germination of the pollen. The flowers were collected at the scheduled hours and the pollen grains were taken from the anthers, by using a brush \# 2. They were then inoculated on Petri dishes containing the culture medium. The completely randomized experimental design was used with four replicates, and each plot was constituted by two Petri dishes. One hundred pollen grains were counted in each Petri dish. After six hours of inoculation, the pollen grains were visualized under magnifying glass. Those pollen grains containing the pollinic tube with the same or higher size than their own pollen diameter were considered germinated. No significant differences were found among the different hours of the pollen grain collections, and the germination percentage ranged from $46.75 \%$ to $53.62 \%$.

Index terms: Annona squamosa, pollination management, in vitro pollen germination.

(Recebido em 8 de novembro de 2006 e aprovado em 21 de dezembro de 2007)

\section{INTRODUÇÃO}

O cultivo da pinha (Annona squamosa L.) vem experimentando um considerável crescimento no Sudeste e Nordeste brasileiro, notadamente nos perímetros irrigados, pela possibilidade de obtenção de mais de uma safra por ano e em razão dos bons preços obtidos para a fruta nos principais mercados consumidores do país (Araújo et al. 1999). No Brasil, são cultivados 6.625 ha com pinha, sendo que a região do nordeste brasileiro é responsável por $93,23 \%$ deste total. O principal produtor

\footnotetext{
'Engenheira Agrônoma, Doutora em Genética e Melhoramento de Plantas, Professora - Departamento de Ciências Agrárias - Universidade Estadual de Montes Claros/UNIMONTES - Campus Universitáro Professor Darcy Ribeiro, Prédio 05, Sala 206 - Cx. P. 126 - $39401-089$ - Montes Claros, MG silvia.nietsche@unimontes.br

Engenheiro Agrônomo, Doutor em Fitotecnia - Departamento de Ciências Agrárias - Universidade Estadual de Montes Claros/UNIMONTES - Avenida Reinaldo Viana, 2630 - Bico da Pedra - Cx. P. 91 - 39440-000 - Janaúba, MG - marlon.pereira@unimontes.br

${ }^{3}$ Engenheiro Agrônomo, Mestre - Departamento de Ciências Agrárias - Universidade Estadual de Montes Claros/UNIMONTES - Avenida Reinaldo Viana, 2630 - Bico da Pedra - Cx. P. 91 - 39440-000 - Janaúba, MG - carpegianeper@bol.com.br

${ }^{4}$ Mestre em Produção Vegetal - Departamento de Ciências Agrárias - Universidade Estadual de Montes Claros/UNIMONTES - Avenida Reinaldo Viana, 2630 - Bico da Pedra - Cx. P. 91 - 39440-000 - Janaúba, MG - marciamaridias@yahoo.com.br

${ }^{5}$ Doutor em Forragicultura e Pastagens - Departamento de Ciências Agrárias - Universidade Estadual de Montes Claros/UNIMONTES - Avenida Reinaldo Viana, 2630 - Bico da Pedra - Cx. P. 91 - 39440-000 - Janaúba, MG - sidnei.reis@unimontes.br
} 
nacional é o Estado da Bahia, seguido de Pernambuco e Alagoas (IBGE, 2001). No estado de Minas Gerais, a cultura tem crescido consideravelmente nos últimos anos, principalmente nos perímetros irrigados da região Norte do estado, destacando os municípios de Jaíba, Janaúba e Nova Porteirinha (CODEVASF, 2003).

São vários os fatores que afetam diretamente a produção das espécies cultivadas do gênero Annona, mas, indubitavelmente, aquele que envolve o processo de polinização é o mais importante. A análise da fertilidade do pólen é condição indispensável ao melhoramento genético, sendo que os dados sobre viabilidade e germinação dos grãos de pólen são fundamentais para os estudos da biologia reprodutiva, desenvolvimento de programas de melhoramento e quando se tem em mente o cultivo racional e comercialização de anonáceas (Flanklin et al., 1995, Lederman et al., 1997).

Um dos principais entraves para melhorar a produtividade da cultura é o baixo índice de pegamento da polinização e, conseqüente formação de frutos. Embora a pinheira produza uma grande quantidade de flores a cada safra, estima-se que somente cerca de 3 a $5 \%$ de frutos efetivamente se formem. Além disso, os frutos são, na sua maioria, desclassificados como pequenos e/ou malformados, possivelmente em decorrência do baixo número de carpelos polinizados (Fioravanço \& Paiva, 1994; Lemos et al., 1999).

Um dos problemas desse baixo número de carpelos polinizados pode ser atribuído à baixa viabilidade dos grãos de pólen que pode ser alterada com a variação da umidade e temperatura do ambiente (Lemos et al. 1999). A polinização realizada de forma ineficiente também é um fator que limita a produção da espécie. Vários são os fatores que podem influenciar esta prática, dentre eles destaca-se o horário da polinização (Zayas, 1966, Bonaventure, 1999 e Pereira et al., 2003), a polinização de maior número de carpelos nas flores funcionalmente pistiladas, a maturação do pólen (Araújo et al. 1999) e a polinização de flores maiores (Nietsche et al. 2002).

Testes de viabilidade de pólen realizados por Kumar et al. (1977), em flores de pinheira coletadas em diferentes épocas, sob as condições da Índia, indicaram que o mês de agosto foi o mais apropriado para a obtenção de grãos de pólen viáveis. Segundo esses autores, a alta umidade do ar predominante naquele mês, foi o fator determinante para que a percentagem de pólens férteis atingisse 73,3\%. Estudos de viabilidade de grãos de pólen de pinheira realizados por Sulikeri et al. (1975) na Índia, observaram em torno de $80 \%$ de viabilidade dos grãos de pólen, quando coletados às 03:00 horas.
O estudo da biologia floral tais como fenologia, viabilidade, germinação dos grãos de pólen e métodos de polinização são imprescindíveis para maximizar algumas práticas de manejo e melhoramento genético da cultura (Bueno, 2002).

Conduziu-se este trabalho, com o objetivo de avaliar a viabilidade dos grãos de pólen de flores de pinheira em diferentes horários de coleta no Norte de Minas Gerais.

\section{MATERIAL E MÉTODOS}

As flores foram coletadas a partir de um pomar de pinheira localizado no Campus de Janaúba, Janaúba, MG. Os ensaios foram realizados a partir de flores no estádio funcionalmente estaminada (estádio "macho"), coletadas no dia 15/08/2005. Foram selecionados 8 horários de coleta dos grãos de pólen: zero hora, 1 hora, 2 horas, 3 horas, 4 horas, 5 horas, 6 horas e 7 horas, cujas temperaturas registradas foram de $23,0{ }^{\circ} \mathrm{C}, 22,1^{\circ} \mathrm{C}, 19,2{ }^{\circ} \mathrm{C}, 18,8^{\circ} \mathrm{C}, 18,3$ ${ }^{\circ} \mathrm{C}, 18,0{ }^{\circ} \mathrm{C}, 17,6{ }^{\circ} \mathrm{C}$ e $19,2{ }^{\circ} \mathrm{C}$, respectivamente, e umidade relativa média de $72,1 \%$ no período. Foi utilizado meio de cultura padrão para germinação de pólen $\left(5 \mathrm{~g} . \mathrm{L}^{-1}\right.$ de Agar, $1,27 \mathrm{mM}$ de $\mathrm{Ca}\left(\mathrm{NO}_{3}\right)_{2} 4 \mathrm{H}_{2} \mathrm{O}, 0,87 \mathrm{mM}$ de $\mathrm{MgSO}_{4} 7 \mathrm{H}_{2} \mathrm{O}$, $0,99 \mathrm{mM}$ de $\mathrm{KNO}_{3}$ e $1,62 \mathrm{mM} \mathrm{H}$ BO a pH 7,0) (Brewbaker \& Kwack, 1963), com concentração de sacarose de 100 g.L. ${ }^{-1}$. $\mathrm{O}$ meio de cultura foi aquecido em forno microondas até próximo do ponto de fervura $\left(95^{\circ} \mathrm{C}\right)$. Em seguida, foi transferido $10 \mathrm{ml}$ do meio para as placas de Petri.

As flores no estádio funcionalmente estaminada foram coletadas manualmente e acondicionadas em sacola plástica e, logo após a coleta, em cada horário préestabelecido, conduzidas ao Laboratório de Fisiologia Vegetal. Os grãos de pólen foram retirados das anteras com auxílio de um pincel número 2 e em seguida inoculados em placas de Petri contendo o meio de cultura padrão para germinação de grãos de pólen. Essa prática foi realizada para os oitos horários estabelecidos.

O delineamento experimental foi inteiramente casualizado, com quatro repetições, sendo cada parcela experimental constituída por duas placas de Petri. Foram avaliadas oito placas por horário e contados 100 grãos de pólen por placa de Petri, totalizando 800 grãos de pólen por horário de avaliação. Após 6 horas de inoculação, para cada um dos tratamentos, as placas foram visualizadas com auxílio de uma lupa (Ken-A-Vision-3310), realizando a contagem dos grãos de pólen. Foram considerados germinados os grãos de pólen que possuíam tubo polínico com tamanho igual ou superior ao diâmetro do próprio pólen.

Em função de o número de grãos de pólen ser classificado com uma variável quantitativa discreta, 
resultante de dados de contagem, testou-se através do procedimento General Linear Models (GLM) (SAS Institute, 2000) a aditividade, através da análise de covariância dos valores preditos ao quadrado, obtendo-se $\mathrm{P}=0,4261$; a normalidade através do procedimento univariate, com a estatística W (Shapiro-Wilk), com P=0,2395 e a homogeneidade de variância pelo teste de Bartlett $(\mathrm{P}=0,0695)$. Uma vez confirmada a não significância destes testes, indicando que a pressuposição de aditividade do resíduo, normalidade do resíduo e homogeneidade de variâncias forma aceitas, as características avaliadas foram submetidas à análise de variância e, quando o teste de F foi significativo, as médias de tratamentos, foram comparadas pelo teste de Tukey, ao nível de 5\% de probabilidade. A análise foi realizada com o utilizando o software estatístico SAS (SAS Institute, 2000), conforme o modelo estatístico a seguir:

$$
Y_{i j}=\mu+C_{i}+e_{i j}
$$

Em que:

$\mathrm{Y}_{\mathrm{ij}}=$ Observação referente à hora de coleta "i”", na repetição "j";

$\mu=$ Média geral;

$\mathrm{C}_{\mathrm{i}}=$ Efeito da hora de coleta " $\mathrm{i}$ ", com $\mathrm{i}=1,2, \ldots 8$;

$\mathrm{e}_{\mathrm{ij}}=$ Erro experimental associado a todos o valores observados que, por hipótese tem distribuição normal com média zero e variância $\sigma^{2}$.

\section{RESULTADOS E DISCUSSÃO}

Não foram observadas diferenças significativas $(\mathrm{P}>0,05)$ para a característica de percentagem de germinação dos grãos de pólen de pinheira entre os diferentes horários de coleta. A porcentagem de germinação variou de 53,62\%, quando polens foram coletados às $03: 00 \mathrm{~h}$ à $46,75 \%$, quando os polens foram coletados às 0:00h (Tabela 1).

De acordo com Bonaventure (1999), a umidade do ar é um fator muito importante para uma boa polinização e frutificação. A umidade atmosférica deve ser superior a $80 \%$ e a temperatura entre $22^{\circ} \mathrm{C}$ e $27^{\circ} \mathrm{C}$. A temperatura e umidade média de $19,5^{\circ} \mathrm{C}$ e $72,1 \%$, respectivamente, encontradas, no momento da coleta dos grãos de pólen, podem ter sido fatores determinantes para a germinação dos mesmos. Os resultados obtidos foram superiores àqueles encontrados por Santos et al. (2003) relatam uma porcentagem de germinação dos grãos de pólen de pinheira de apenas $13,75 \%$, quando as flores foram coletadas entre 7 horas e 10 horas. Estudos realizados por Sulikeri et al. (1975), na Índia, observaram em torno de $80 \%$ de germinação de pólen de pinha, quando as flores funcionalmente estaminadas foram coletadas às 3 horas. As diferenças entre os resultados obtidos e os apresentados por Sulikeri et al. (1975), demonstram que tal característica é muito influenciada pelas diferenças climáticas e a alta umidade é fator determinante para a maior percentagem de polens férteis. De acordo com Dafni (1992), além da umidade relativa do ar a temperatura do ambiente também influência a característica de viabilidade dos grãos de pólen. Em outras espécies o mesmo comportamento pode ser observado, Bueno et al. (2002), estudando a viabilidade dos grãos de pólen de flores de melão (Cucumis melo L.) verificaram que a viabilidade dos grãos de pólen sofre uma queda com o passar do dia, quando ocorre aumento da temperatura e diminuição da umidade relativa do ar.

Tabela 1 - Percentagem de germinação dos grãos de pólen de flores de pinheira coletados em diferentes horários, temperatura e umidade relativa nas condições do Norte de Minas Gerais, Janaúba, 2005.

\begin{tabular}{cccc}
\hline Horário de Coleta & $\begin{array}{c}\text { Germinação dos Grãos } \\
\text { de Pólen }(\%)\end{array}$ & Temperatura $\left({ }^{\circ} \mathrm{C}\right)$ & Umidade Relativa $(\%)$ \\
\hline $00: 00$ & 46,75 & 23,0 & 51 \\
$01: 00$ & 47,50 & 22,1 & 68 \\
$02: 00$ & 51,37 & 19,2 & 69 \\
$03: 00$ & 53,62 & 18,8 & 74 \\
$04: 00$ & 49,68 & 18,3 & 78 \\
$05: 00$ & 50,87 & 18,0 & 80 \\
$06: 00$ & 51,00 & 17,6 & 83 \\
$07: 00$ & 51,06 & 19,2 & 74 \\
\hline
\end{tabular}


Estudos realizados por Judd et al. (1999), confirmam que a viabilidade dos grãos de pólen pode ser alterada com a variação da umidade e temperatura do ambiente, e pode ser testada por meio da capacidade de germinação, por atividade enzimática, e pela presença de citoplasma. Esta variação também pode ser própria da espécie, a exemplo de algumas gramíneas que podem apresentar viabilidade de minutos ou horas, enquanto grãos de pólens de outras podem permanecer viáveis por vários anos se armazenados adequadamente.

Trabalhos conduzidos por Nunes et al. (2004), com grãos de pólen de flores de atemoieira coletados em diferentes horários, entre 7 horas e 10 horas, e inoculados em meios de cultura com diferentes concentrações de sacarose, indicaram que os grãos de pólen coletados às 7:00 horas e inoculados em meio de cultura com concentração de sacarose de $10 \%$, apresentaram maior percentagem de germinação, com média de $12,25 \%$.

Estudos realizados por Nietsche et al. (2002), avaliando o pegamento e qualidade de frutos de pinheira em diferentes horários de polinização das flores, determinaram que porcentagens superiores a $90 \%$ de pegamento dos frutos foram obtidas quando as flores foram polinizadas a partir das 7 horas.

De acordo com Kavati (1997) e Santos et al. (2003), uma flor de pinheira tem em média 150 carpelos. Portanto, após ser polinizada, uma flor poderia gerar um fruto com até 150 sementes. Entretanto, o que vem sendo observado em inúmeros trabalhos, Araújo et al. (1999), Pereira et al. (2003) e Nietsche et al. (2002), são médias de 85 sementes/ fruto. Podemos então considerar que apenas $56 \%$ dos carpelos estão sendo fertilizados, corroborando com os resultados obtidos da viabilidade dos grãos de pólen in vitro. Estes resultados de baixa fertilização dos carpelos podem estar associados ao tamanho da flor (Santos et al., 2003), número de carpelos por flor (Kavati,1997), horário de polinização (Pereira et al, 2003), viabilidade do pólen (Sulikeri et al,1975 e Santos et al,2003), condições climáticas (Dafni et al, 1992), e genótipo da planta.

\section{CONCLUSÃO}

Pólens coletados entre zero hora às 7 horas apresentaram a mesma porcentagem de germinação, indicando que a coleta das flores de pinheira, para a polinização artificial, pode ser realizada às 7 horas, sem redução da viabilidade dos grãos de pólen de pinheira.

\section{AGRADECIMENTOS} trabalho.

\section{REFERÊNCIAS BIBLIOGRÁFICAS}

ARAÚJO, J. F., ARAÚJO, J. F.; ALVES, A. A. C. Instruções

técnicas para o cultivo da pinha (Annona squamosa L.). Salvador: EBDA, 1999. 44p. (Circular Técnica, 7).

BONAVENTURE, L. A cultura da cherimóia e de seu híbrido a atemóia. São Paulo, Ed. Nobel, 1999. 181p.

BREWBAKER JL, KWACK BH The essential role of calcium íon in pollen germination and pollen tube growth. American Journal of Botany,.48:457-469, 1963.

BUENO, D. M; CAVALCANTE, K. L. Estudo da viabilidade dos grãos de pólen de flores de melão (Cucumis melo L.). In: CONGRESSO BRASILEIRO DE FRUTICULTURA, 17, Belém. Anais... CBF: Belém, 2002.

CODEVASF. Relatório de fases produtivas, programa de fruticultura. 2003. Disponível em: uwww.codevasf.org.br?. Acesso em: julho de 2003.

DAFNI, A. Pollination ecology: a pratical approach. Oxford University Press, 1992. 250 p.

FIORAVANÇO, J.C.; PAIVA, M.C. Tratos culturais. In: FIORAVANÇO, J.C.; PAIVA, M.C. (Eds.) Fruticultura, cultivo das anonáceas: ata, cherimóia e graviola. Porto Alegre: EVANGRAF, 1994. Cap. 8, p.62-77.

\section{FLANKLIN F.H.C.; LAWRENCE, M.J.; FLANKLIN-}

TONG, V.E. Cell and molecular biology of selfincompatibility in flowering plants. International Rewiew of Cytology, v.158, p.1-62, 1995.

IBGE. Levantamento Sistemático da Produção Agrícola 2001. Disponível em: <www.sidra.ibge.gov.br/sidra/agroh agro.htm>. Acesso em: julho de 2001 .

JUDD, W.S.; CAMPBELL, P.S.; QELLOGG, E.A.; STEVENS, P.S. Plant sytstematics: a phylogenetic approach. Sinaver, 1999. 464 p.

KAVATI, R. Cultivo da atemóia. In: DONADIO, L.C.; MARTINS, A. B. G.; VALENTE, J. P. Fruticultura

Tropical. Jaboticabal: FUNEP, 1992. 325p.

KUMAR, R.; HONDA, M.N.; SINGH, D.K. Studies on the floral biology of Custard apple (Annona squamosa Linn.). Indian Journal of Horticulture, Bangolore, v.34, n.3, p.252-256, 1977. 
LEDERMAN, I. E.; BEZERRA, J. E. F. Indução e polinização de anonáceas. In: SÃO JOSÉ, A . R.; SOUZA, I. V. B.; MORAIS, O . M.; REBOUCAS, T. N. H. (Ed.) Anonáceas: produção e mercado (pinha, graviola, atemóia e cherimóia). Vitória da Conquista: UESB-DFZ, 1997. 142-148.

LEMOS, E. E. P.; PEREIRA, P. C. C.; CAVALCANTE, R. L. R. Artificial pollination of Soursop (Annona muricata L.), to improve fruit yield and quality. In: CONGRESSO INTERNACIONAL DE ANONÁCEAS, 2., Tuxtla Gutiérrez, Chiapas, México. Anais... 1999. p. 97

NIETSCHE, S.; PEREIRA, M. C. T.; SANTOS, F. S; XAVIER, A. P.; CUNHA, L. V.; NUNES, C. F.; MARTINS, T. T. S. Efeito de horários de polinização artificial no pegamento e qualidade de frutos de pinha (Annona squamosa L.). In: CONGRESSO BRASILEIRO DE FRUTICULTURA, 17, Belém. Anais... CBF: Belém, 2002.

NUNES, C. F. Polinização artificial e natural de atemóia cultivar "Gefner", viabilidade do grão de pólen e correlação entre comprimento de flor e número de carpelos. Janaúba. 2004. 55p. (Monografia de Conclusão de Curso)- Universidade Estadual de Montes Claros, Janaúba, 2004.

PEREIRA, M.C.T.; NIETSCHE, S.; SANTOS, F.S.; XAVIER, A.A.; CUNHA, L.M.V., NUNES, C.F., SANTOS, F.A. Efeito de horário de polinização artificial no pegamento e qualidade de frutos de pinha (Annona squamosa L.). Revista Brasileira de Fruticultura, Jaboticabal, v.25, n.2, p.203-205, 2003.

SANTOS, F. S. Polinização artificial de flores de pinheira (Annona squamosa L.) em diferentes tamanhos e horários. Janaúba. 2003. 35p. (Monografia de Conclusão de Curso)-Universidade Estadual de Montes Claros, Janaúba, 2003.

SAS INSTITUTE. SAS/STAT User's guide. Version 8. Cary, NC, 2000.

SULIKERI, G. S; NALAWADI, U. G.; SINGH, C. D. Pollen viability studies in Annona squamosa L. Current Research, v. 4, n. 2, p. 31-32, 1975.

ZAYAS, J. C. Las Frutas Anonáceas. Habana, La Habana, 1966. 61p. 